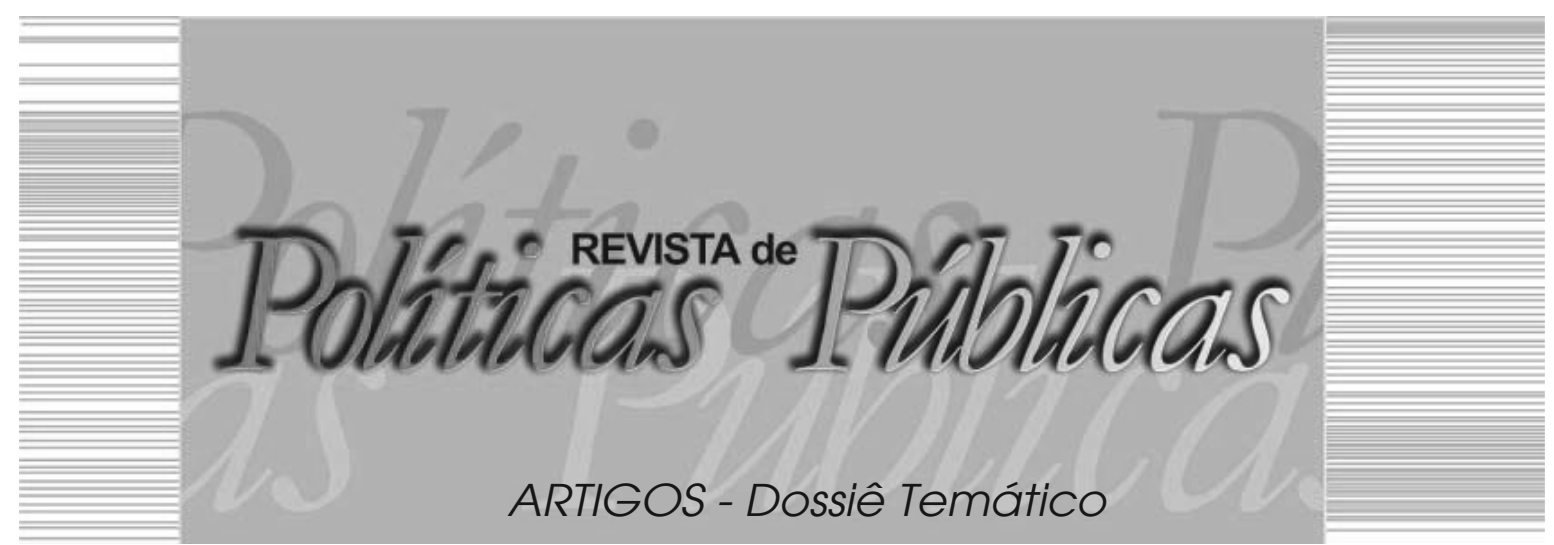

\title{
AGENDA GOVERNAMENTAL E POLITICAS CULTURAIS: ascensão e mudanças na policy image do Plano Nacional de Cultura
}

\author{
Samira Chedid ${ }^{l}$ \\ Ana Cláudia Niedhardt Capella
}

\section{Resumo}

O Plano Nacional de Cultura foi formulado para dar maior estabilidade e continuidade às políticas culturais brasileiras. Nesse sentido, o principal objetivo deste trabalho consistiu em identificar e analisar como o Plano ascendeu à agenda governamental e como ele foi entendido e discutido na agenda do Poder Legislativo e do Poder Executivo ao longo de doze anos (2003-2014). Para tanto utilizamos o conceito de imagem da política (policy image), oriundo do modelo de Equilíbrio Pontuado em que se sustenta a existência tanto de momentos estáveis e incrementais na agenda governamental, como de mudanças repentinas e profundas. Os resultados mostraram que a imagem do PNC chegou ao ápice em determinados períodos permeados por intervalos estáveis, fato que

\footnotetext{
Bacharel em Ciências Sociais, Mestre em Ciência Política pela Universidade Federal de São Carlos (UFSCAR), Assistente de Pesquisa no Insituto de Pesquisa Econômica Aplicada (IPEA) (bolsista). E-mail: samirachedid@gmail.com / Endereço: Insituto de Pesquisa Econômica Aplicada - IPEA: SBS - Quadra 1 - Bloco J - Ed. BNDES - Brasília DF. CEP: 70076-900

2 Bacharel em Administração Pública, Doutora em Ciências Sociais pela UFSCar, Professora na Universidade Estadual Paulista (UNESP), no Programa de Pós-Graduação em Ciência Política(PPG-POL)edoMestradoProfissionalemGestãodeOrganizaçõeseSistemasPúblicos (PPG-GOSP), da Universidade Federal de São Carlos (UFSCar). E-mail: acapella@terra. com.br / Endereço: Universidade Federal de São Carlos - UFSCar: Rod. Washington Luís km 235 - SP-310 - São Carlos. CEP: 13565-905; Universidade Estadual Paulista Júlio de Mesquita Filho - UNESP: Faculdade de Ciências e Letras - Campus de Araraquara, Rodovia Araraquara-Jau, Km 1 - Departamento de Administração Pública - Araraquara, SP. CEP: 14800-901
} 
nos permite afirmar a existência de mudanças na percepção das políticas culturais ao longo do tempo.

Palavras-chave: Agenda governamental, teoria do equilíbrio pontuado, políticas públicas culturais, plano nacional de cultura, policy images.

GOVERNMENTAL AGENDA AND CULTURAL POLICIES: ascension and changes in policy image of Cultural National Plan

\begin{abstract}
The Cultural National Plan (PNC) has been formulated to give more stability and continuity to the Brazilian cultural public policies. In that sense, the main objective of this article is to identify and analyze how the Plan has ascended to the governmental agenda and how it was discussed in the Legislative and Executive powers throughout twelve years $(2003$ - 2014). In order to achieve this study, the policy image concept was used, from the Punctuated Equilibrium model, in which it sustains the existence of stable and incremental moments in the government agenda, as well as sudden and deep changes. The results show that the PNC's image has achieved its peak in some periods among stable intervals, which makes it possible to claim the existence of changes in the cultural policies perception throughout time.

Key words: Governmental agenda, Punctuated Equilibrium Theory, cultural public policies, Cultural National Plan, policy images.
\end{abstract}

\title{
1 INTRODUÇÃO
}

Se a cultura se configura como um direito, o Estado deve incentivá-la e preservá-la em todas as suas formas e expressões. É função do Estado criar mecanismos para preservar e incentivar a cultura no que se refere ao orçamento, leis específicas para cada setor cultural, democratização do acesso, e às políticas culturais, e abertura de diálogo para com a sociedade.

No Brasil, embora o campo cultural já estivesse reconhecido na organização do Estado por meio da Constituição de 1988, as políticas culturais foram marcadas por frequentes descontinuidades, limitando o pleno desenvolvimento das ações relacionadas ao campo da cultura. A ausência de institucionalização das políticas de cultura é reconhecida como fator de instabilidade para as ações, programas e projetos desenvolvidos na área. Nesse sentido, no ano 2000, os deputados Gilmar Machado (PT/MG) e Marisa Serrano (PSDB/MS) apresentaram o Projeto de Emenda Constitucional (PEC) n $\mathrm{n}^{\circ} 306-\mathrm{A}$, 21 de março de 2017, que acrescenta ao artigo 215 da Constituição 
Federal (CF), em seu terceiro parágrafo, o Plano Nacional de Cultura (PNC). Certamente, a aprovação desta PEC se configura como um marco institucional decisivo no âmbito cultural, pois passa a tratar a cultura não mais como uma política de governo, mas como uma política de Estado.

Três anos após a PEC 306-A, e quinze anos após a Constituição de 1988, o PNC passa a integrar de maneira intensa a agenda do governo federal e, em 2005 a PEC n ${ }^{0} 306-\mathrm{A} / 2017$ resultou na Emenda Constitucional (EC) no 48, de 10 de agosto de 2005, aprovada pelo Congresso em julho, determinando que o Plano seja elaborado como lei e realizado de forma plurianual. Assim, por meio da articulação do Congresso Nacional, tem início a discussão do PNC. A iniciativa não partiu do Poder Executivo e nem do próprio Ministério da Cultura (MinC)1.

Finalmente aprovado em 2009 e criado pela Lei no 12.343 , de 2 de dezembro de 2010, o PNC orienta as políticas culturais em todo o território brasileiro. Para que seja colocado em prática, é necessário que estados e municípios façam a adesão do mesmo através do Sistema Nacional de Cultura (SNC), um modelo que compartilha a gestão das políticas culturais, entre a federação, os Estados e os municípios. Por esse ângulo, a construção de um plano a nível nacional tornou-se de extrema relevância para direcionar o poder público na formulação de políticas públicas culturais. É por meio da institucionalização do PNC, através do Sistema Nacional de Cultura (SNC), que tais políticas têm a possibilidade de adquirir estabilidade e continuidade.

O PNC é o primeiro planejamento a longo prazo específico do campo cultural que tem sua formulação no Estado democrático de direito do Brasil, ou seja, nunca antes na história do país uma política pública cultural com essa dimensão chegou a ser aprovada e passou a integrar a agenda do governo federal (lembrando que em meados da década de 1970 um plano chegou a ser escrito, porém não foi aprovado).

Pautado por três dimensões: simbólica, cidadã e econômica, onde a cultura como expressão simbólica, assinala que todos os seres humanos podem criar símbolos, que devem ser reconhecidos e valorizados. Tais símbolos se expressam em modos de vida, de saberes e identidades e nas mais distintas atividades culturais, como os costumes, crenças, idiomas, arquitetura, teatro, dança, música, circo, 
artes visuais, dentre outros. Nessa perspectiva, a dimensão referida se relaciona ao bem-estar do ser humano no âmbito individual e coletivo.

A cultura como direito de cidadania, sustenta que a cultura é um direito básico de todo cidadão, que deve ser garantida por meio de políticas que ampliem o acesso aos bens e serviços culturais, assim como aos mecanismos de participação social. Enfim, a terceira dimensão, e não menos importante, que completa o tripé de eixos do PNC, está a cultura como potencial para o desenvolvimento econômico. Esta dimensão considera a cultura como geradora de lucro, emprego e renda, e estimuladora de cadeias produtivas que se relacionem com a economia criativa e com as expressões artísticas, desenvolvimento econômico socialmente justo e também sustentável.

Tendo isso em vista, faz-se necessário compreender em profundidade como se deu todo o processo de articulação política que levou o tema do PNC à agenda do governo federal e ocasionou esse grande salto nas políticas culturais brasileiras. Surge assim a seguinte problemática: como o PNC começou a ser tratado como um problema público até emergir na agenda governamental, e qual foi a atenção dada ao longo do tempo antes e após se tornar lei? Isto é, o que foi debatido, proposto e aprovado sobre o PNC e seu respectivo conteúdo? Qual foi a imagem construída a seu respeito? Houve um momento de grande mudança balanceado por períodos de equilíbrio?

Partindo dessas questões, o objetivo deste artigo consiste em analisar o PNC, ao longo de doze anos, buscando entender como o Plano passa a integrar a agenda dos Poderes Legislativo e Poder Executivo. Para tanto, utilizaremos a Teoria do Equilíbrio Pontuado, proposta por Baumgartner e Jones (1993, 2002), segundo a qual as mudanças em políticas públicas - sejam mudanças graduais ou súbitas - estão relacionadas à forma como a discussão sobre as políticas são estruturadas nos subsistemas políticos. Sob tais premissas, parte-se da hipótese de que o debate em torno do PNC era caracterizado por um relativo equilíbrio dentro do subsistema do setor cultural, situação que muda rapidamente após a entrada de novos atores governamentais no ano de 2003. Nesse momento, o PNC passa por mudanças rápidas e passa a fazer parte efetivamente da agenda governamental.

Do ponto de vista metodológico, a investigação emprega a técnica de análise de conteúdo de documentos oficiais relaciona- 
AGENDA GOVERNAMENTAL E POLÍTICAS CULTURAIS: ascensão e mudanças na policy image do Plano Nacional de Cultura

dos ao PNC, para a identificação das temáticas específicas que integraram os debates tanto no âmbito do Poder Legislativo quanto do Executivo. ${ }^{2}$ Para isso, primeiro foi realizado o levantamento do corpus documental composto pelos seguintes documentos: medidas provisórias, projetos de lei, leis, leis complementares e emendas constitucionais ${ }^{3}$ para identificar os temas presentes na agenda do Legislativo; medidas provisórias, leis e leis complementares, discursos do presidenciais e Mensagens ao Congresso para identificação da agenda do Executivo ${ }^{4}$. Acrescentam-se, ademais, os discursos proferidos pelos (as) ministros (as) de cultura ao longo do período apontado. Após o levantamento do corpus documental, a segunda fase foi composta pela identificação e mapeamento das temáticas ${ }^{5}$ referentes ao PNC abordados nos documentos indicados.

Como resultado, os dados analisados indicam que a questão da cultura ainda não figura como um tema central na agenda governamental brasileira, pois embora os debates sobre a política de cultura tenham sido mais frequentes a partir da formulação do PNC, ocupado posição de destaque em variados discursos e propostas legislativas, após se tornar lei o tema deixa de concentrar a atenção dos formuladores de política. Por meio da pesquisa, observou-se também a proeminência de alguns temas específicos no campo das políticas culturais, como financiamento, patrimônio cultural e questões relacionadas ao audiovisual. Por outro lado, as artes como um todo constituem temas marginais nos debates.

\section{AGENDA GOVERNAMENTAL E O CONCEITO DE POLICY IMAGES}

Baumgartner e Jones (1993), ao se debruçarem no estudo do processo de formulação de políticas públicas, desenvolveram a Teoria do Equilíbrio Pontuado - Punctuated Equilibrium Theory (PET). Em resumo, tal teoria sustenta que o processo das políticas públicas é conduzido no sentido da estabilidade e do incrementalismo e, por outro lado, pode ocasionar significativas mudanças (pontuações). Algumas vezes, as políticas públicas são extremamente resistentes às mudanças, seguindo um procedimento normal e trabalhando dentro das normas de consenso; assim, atrai uma pequena atenção pública e muda muito pouco. Em outros momentos, ocorrem mudanças drásticas, principalmente quando novos problemas surgem na 
agenda política, e crises requerem uma resposta rápida do governo (BAUMGARTNER; JONES, 2002).

Para compreender os períodos de estabilidade e mudança é preciso entender como determinada questão é definida, salientando que tal definição está inserida num contexto institucional que privilegia algumas perspectivas políticas e não outras. Segundo Baumgartner e Jones (1993), as questões políticas e sociais não se transformam em problemas de maneira automática, mas é necessário que por meio de uma imagem ou através do consenso de uma política, ligue-se o problema e uma solução, pois um argumento deve ser elaborado e aceito como um problema passível de ser resolvido pela ação do governo antes de uma condição social vir a ser um problema de política pública.

A questão da imagem da política pública está intrinsecamente ligada à agenda governamental visto que a agenda diz respeito ao que se fala sobre um assunto, isto é, a incidência do tema no debate. E a imagem ou a percepção se refere ao modo como se fala sobre determinado assunto. Assim, quanto maior a incidência, maior é sua presença na agenda. Dessa maneira, as policy images dizem respeito a como determinada política é entendida e discutida, ou seja, nada mais são do que ideias que fundamentam os arranjos institucionais e assim proporcionam uma comunicação simples e direta entre determinada comunidade, fundamental para uma questão ascender ao macrossistema e, cujo desenvolvimento ocorre a partir de informações empíricas e apelos emotivos, que os autores se referem como tones.

Desse modo, a agenda política é estável até emergir uma nova questão sobre determinado tema. É preciso salientar ainda que, a imagem de determinado assunto muda do âmbito privado para um problema passível de solução governamental e assim entra na agenda do governo. Quando o problema é levado à agenda, não traz consigo uma solução específica. Há algumas ou muitas políticas que o governo deve adotar para finalmente resolver o problema. Não se deve esquecer que muitos interesses estão em jogo neste momento e são afetados de acordo com a solução escolhida. (BAUMGARTNER; JONES, 1993).

Uma nova imagem pode atrair novos participantes e múltiplos contextos institucionais. Cada contexto institucional possui sua própria linguagem, uma configuração de participantes, limitações, 
AGENDA GOVERNAMENTAL E POLÍTICAS CULTURAIS: ascensão e mudanças na policy image do Plano Nacional de Cultura

importante para envolver estratégias entre quem tenta afetar o processo de agenda-setting. Assim, as instituições e grupos na sociedade têm a autoridade para tomar decisões em relação a determinado assunto.

Ao tratar da interação entre imagem e contexto institucional no Modelo de Equilíbrio Pontuado, os autores apontam que o grau em que os problemas são firmemente ligados a imagens é relacionado ao grau que uma única arena de policymaking exerce um controle monopolístico sobre uma política. Assim, quando as imagens mudam, ocorrem também mudanças institucionais. Da mesma forma, onde contextos institucionais mudam, o debate também pode se alterar. Por outro lado, quando os contextos institucionais são fortemente controlados, as mudanças nas imagens são menos prováveis. E, onde mudanças nas imagens são descartadas, a probabilidade de afetar mudanças nos contextos institucionais é baixa. Em suma, imagem e contexto institucional podem levar juntos, a mudanças rápidas ou podem reforçar algo já existente. (BAUMGARTNER; JONES, 1993).

Quando dominado por um único interesse, o subsistema é mais bem refletido no monopólio da política. Este tem uma estrutura institucional definível responsável pela formulação numa área, e esta responsabilidade é suportada por algumas ideias de poder ou imagem. Esta imagem é geralmente conectada ao âmago dos valores políticos e pode ser comunicada simples e diretamente ao público. Em suma, nos subsistemas políticos está a política do equilíbrio, a política do monopólio da política pública, do incrementalismo, um amplo suporte da imagem e o feedback negativo. E na macropolítica está a política da pontuação, a política em mudança em larga-escala, competição nas imagens da política, manipulação política, e feedback positivo. (BAUMGARTNER; JONES; MORTENSEN; 2014).

Desse modo, o policy monopoly diz respeito aos mais diversos entendimentos sobre uma questão, e que passam a ser dominantes. Assim, os atores adquirem controle sobre a interpretação de determinado problema. Contudo, há momentos em que novos atores conseguem acessar esses monopólios, gerando instabilidade e a possibilidade de mudar a agenda. Isso ocorre devido à mudança no modo de como a questão é interpretada, isto é, quando a imagem da política muda. E preciso ressaltar também que, as novas ideias e as novas instituições inclinam-se a se manter ao longo do tempo 
(policy legacy), gerando um novo equilíbrio no sistema político que, após certo período de tempo volta à estabilidade.

\section{PRODUCC̃̃O LEGISLATIVA E DISCURSOS DO PODER EXECUTIVO}

Para compreender as mudanças da imagem das políticas culturais ao longo do tempo, classificamos os documentos relativos tanto ao Poder Legislativo como ao Poder Executivo, tomando como referência os temas mais frequentmente apontados nesses documentos. Esta seção apresenta e analisa os dados relacionados à produção legislativa (medidas provisórias, projetos de lei, leis, leis complementares e emendas constitucionais) para identificar os temas presentes na agenda do Legislativo e, em seguida os dados relacionados ao Executivo (discursos presidenciais e dos Ministros da Cultura).

\subsection{Produção legislativa}

Considerando a produção legislativa6, como importante indicador da atenção governamental, observa-se, de acordo com o Gráfico 1, que o tema que mais despertou o interesse e entrou na agenda do legislativo foi o financiamento, com $48 \%$. Em seguida, vềm os assuntos de caráter geral, com $22 \%$, ou seja, a diferença entre o primeiro e o segundo lugar é mais que o dobro, o que demonstra como o financiamento foi debatido na produção legislativa.

Ressalta-se que a Categoria Geral inclui: o PNC; o Sistema Nacional de Cultura, os Pontos de Cultura; o Programa Cultura Viva, o Mais Cultura; e, demais políticas, programas ou projetos culturais com abrangência geral, além do termo "cultura" mencionado de forma isolada, desde que relacionado às políticas públicas culturais, ou quando se trata de dois ou mais subcódigos concomitantemente7. As demais temáticas das políticas culturais distribuídas entre os subcódigos -exceto os projetos de lei do subcódigo X03: Educação, Indicadores e Pesquisa- as restantes, ficaram abaixo de dez propostas. 
AGENDA GOVERNAMENTAL E POLÍTICAS CULTURAIS: ascensão e mudanças na policy image do Plano Nacional de Cultura

Gráfico 1-Temas Culturais na Produção Legislativa

Temas culturais na Produção Legislativa

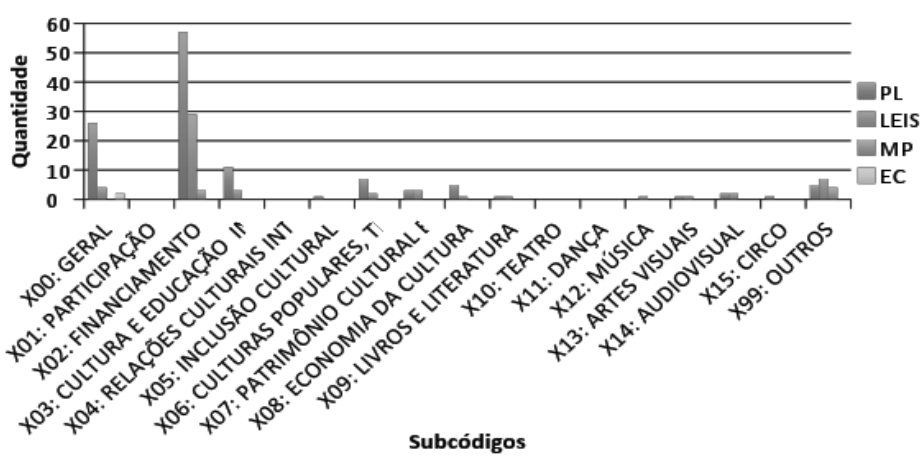

Fonte: Elaborado pelas autoras.

Ao analisar a produção legislativa de acordo com cada mandato presidencial, verifica-se, como demonstra o Gráfico 2, intitulado Produção Legislativa da Cultura por mandato presidencial, que a produção legislativa - contabilizando as emendas constitucionais, medidas provisórias, leis e projetos de lei - do primeiro ano de cada um dos três mandatos presidenciais foi superior aos anos subsequentes a cada mandato, isto é, constatou-se a pontuação, o momento de mudança nestes casos, seguida por períodos constantes de equilíbrio, principalmente no primeiro mandato de Lula e no primeiro de Dilma. Assim, a média desta produção no primeiro mandato de Lula foi 15 por ano; no segundo mandato de Lula a média foi 17 por ano e, no primeiro mandato de Dilma, a média foi 11 por ano.

Gráfico 2 - Produção Legislativa da Cultura por Mandato Presidencial (2003-2014)

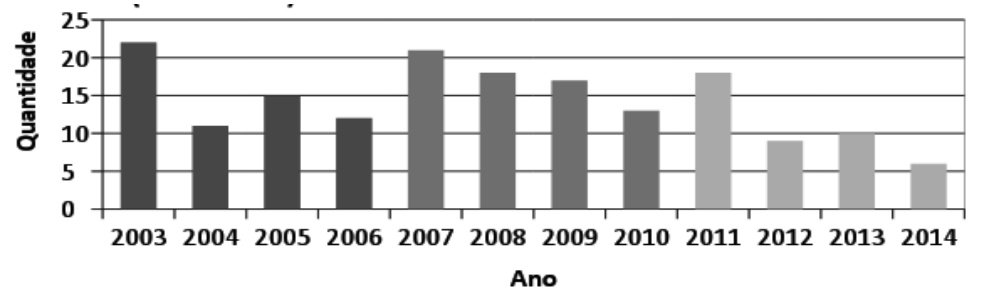

Fonte: Elaborada pelas autqqorasçã. 


\subsection{Participação do Congresso Nacional na Produção Legislativa}

Verificada a produção legislativa em sua totalidade, agora a análise se volta especificamente à atuação do Congresso Nacional dentro da produção legislativa, isto é, todas as emendas constitucionais, medidas provisórias, leis, projetos de lei e leis complementares propostos por deputados ou senadores. Como expressa o Gráfico 3, no Congresso Nacional na Produção Legislativa, houve duas Emendas Constitucionais, com um intervalo de sete anos entre uma e outra: uma em 2005 e outra em 2012. Foram aprovadas sete leis durante esse período, sendo uma em 2003, uma em 2004, uma em 2005, duas em 2008, uma em 2010 e uma em 2011. Quanto aos Projetos de Lei, estes foram propostos em todos os anos analisados, sendo o maior pico no ano de 2011, seguido por 2007 e $2003 \mathrm{com}$ nove projetos cada8.

Gráfico 3 - Congresso Nacional na Produção Legislativa

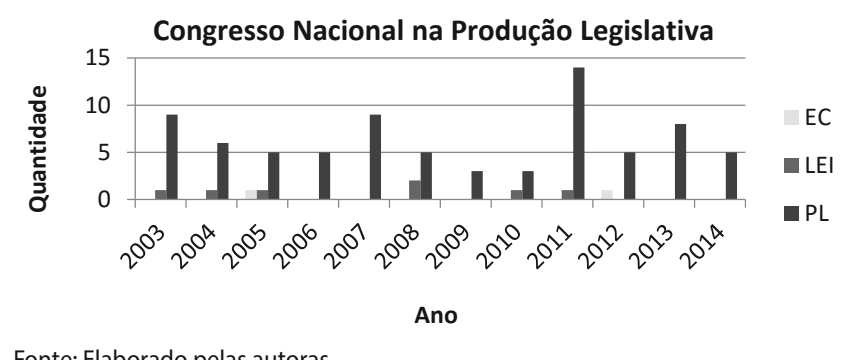

Fonte: Elaborado pelas autoras.

Assim, observa-se que havia uma movimentação considerável na agenda do Poder Legislativo durante o ano de 2003, quando contabilizada toda a produção legislativa, se comparada aos demais anos. Essa movimentação apresenta um deslocamento decrescente até o ano de 2006, voltando ao mesmo patamar em 2007. Novamente cai até 2010, e há o pico em 2011, que segue uma oscilação até o ano de 2014.

Desse modo, fica clara a existência de três momentos em que as políticas culturais despertaram maior atenção do Legislativo, coincidentes com o primeiro ano de cada mandato presidencial, seguidos por períodos com maior estabilidade. Uma vez que o ano de 2011 possui a maior frequência, é possível destacar dois pontos: 
AGENDA GOVERNAMENTAL E POLÍTICAS CULTURAIS: ascensão e mudanças na policy image do Plano Nacional de Cultura

trata-se do primeiro ano que o PNC passa a vigorar como lei e, é o primeiro ano do mandato de Dilma Rousseff. Assim, vê-se o ano de 2011 como o momento de maior diálogo do Poder Executivo com o Congresso Nacional, visto que o PNC deteve grande atenção nesse período.

\subsection{Participação do Poder Executivo na Produção Legislativa}

Reportando-se à atuação do Poder Executivo na produção legislativa, o Gráfico 04 ilustra bem esta participação que, em conjunto, obteve a maior movimentação no triênio 2007-2008-2009. Em 2003 também houve uma movimentação significativa, mas nos anos seguintes sofreu uma queda, assim como ocorreu de 2010 a 2014, sendo que este último ano foi o que apresentou apenas um projeto de lei oriunda do Poder Executivo.

No que se referem às Medidas Provisórias, estas tiveram destaque de 2005 a 2009. Nos demais anos da análise desta pesquisa, as MPs ficaram ausentes. Sobre as Leis, estas apresentaram queda, crescimento e queda novamente até 2011, se ausentando nos anos seguintes. Já os Projetos de Lei se comportaram de maneira instável durante este período, com o pico no ano de 2009. E, em relação às Emendas Constitucionais e Leis Complementares, não houve nenhuma proposta por parte do Executivo.

Gráfico 4 - Poder Executivo na Produção Legislativa (2003-2014)

Poder Executivo na Produção Legislativa

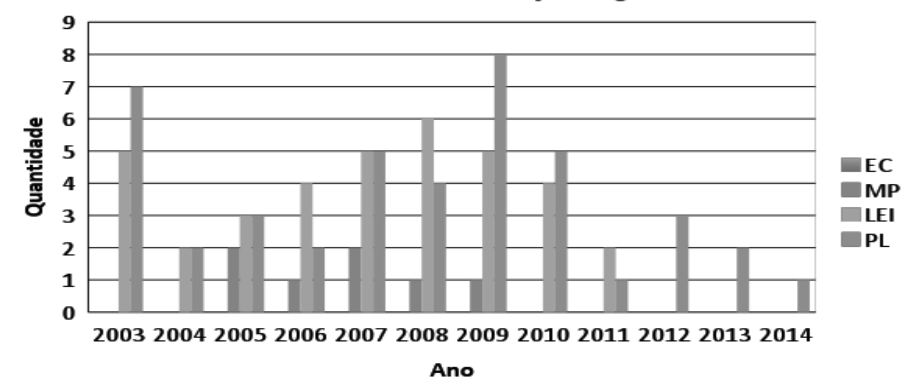

Fonte: Elaborado pelas autoras.

O que foi observado nessa análise, é que a atuação do Executivo e do Legislativo foi exatamente a mesma: $50 \%$ e $50 \%$, o que evidencia o poder de ambos. Dos 42 Projetos de Lei propostos pela 
Presidência da República, 32 foram aprovados, 08 arquivados e 02 seguiram em tramitação.

\subsection{Discursos do Poder Executivo}

O próximo indicador de atenção remete aos discursos do Poder Executivo, que incluem: os Discursos oficiais da Presidência da República, as Mensagens ao Congresso e os discursos proferidos pelo Ministério da Cultura.

\subsubsection{Mensagens ao Congresso e Discursos Presidenciais}

As mensagens enunciadas pela Presidência da República ao Congresso Nacional evidenciam um momento oficial para que o (a) Presidente comunique ao Legislativo as suas prioridades governamentais por meio de um documento escrito. Como demonstra o Gráfico 08, os temas culturais ficaram ausentes do ano de 2003 até o ano de 2010, o que abrange os dois mandatos presidenciais de Lula.

No mandato de Dilma, o ano de 2011 foi o mais representativo de todo o período, pois foram identificados seis subcódigos referentes à cultura. Que são: um sobre audiovisual, um sobre música, um livros e literatura, um economia da cultura, um financiamento e um geral. No ano seguinte, não houve nenhuma menção à cultura; ocorrendo o mesmo em 2014. E, em 2013 houve um subcódigo sobre economia da cultura.

Gráfico 5 - Mensagens ao Congresso Nacional (2003-2014)

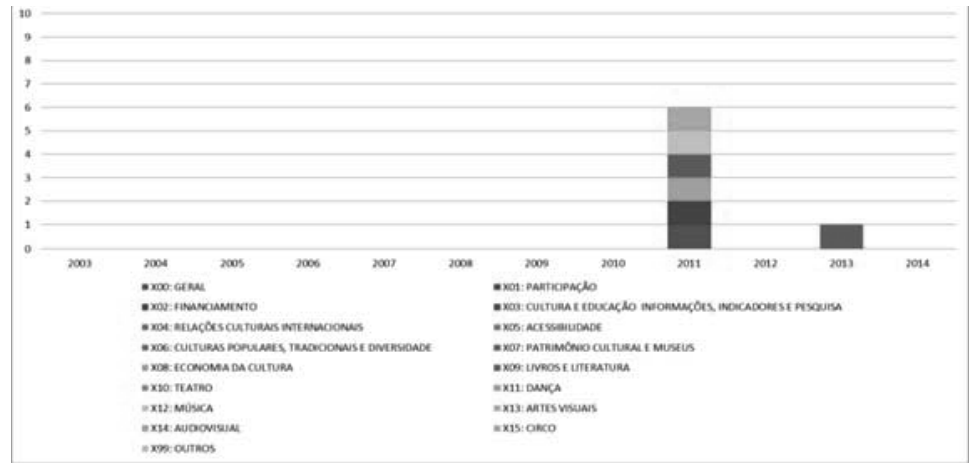

Fonte: Elaborado pelas autoras. 
AGENDA GOVERNAMENTAL E POLÍTICAS CULTURAIS: ascensão e mudanças na policy image do Plano Nacional de Cultura

É interessante constatar, ao observar o Gráfico 05 , a tentativa de aproximar a relação Executivo-Legislativo, já que nos oito anos anteriores, ao menos nas Mensagens ao Congresso, não se menciona nenhuma das temáticas culturais representadas nos subcódigos. Como demonstram os dados acima, o ano de 2011 surge como o de maior movimentação no Congresso Nacional, tanto no que diz respeito ao conteúdo legislativo, como da relação entre Executivo-Legislativo. Fato que reflete no maior número de propostas legislativas, como já ilustrado no Gráfico 4.

No que se refere aos discursos presidenciais oficiais, realizados nas mais diversas ocasiões, de 2003 a 2014, incluindo os discursos de posse, notou-se, como está explícito no Gráfico 09 logo abaixo, que a temática com a maior presença diz respeito ao subcódigo Geral (30,9\%), que abrange o PNC; o Sistema Nacional de Cultura, os Pontos de Cultura; o Programa Cultura Viva, o Mais Cultura; e, demais políticas, programas ou projetos culturais com abrangência geral, além da menção ao conceito cultura de forma isolada, desde que relacionado às políticas públicas culturais, ou quando se trata de dois ou mais subcódigos concomitantemente.

Em seguida vêm os assuntos referentes às Relações Culturais Internacionais (20\%) e Audiovisual $(8,8 \%)$. Somando a categoria Geral, constata-se que foi nos anos de 2009 e 2010 o momento com a maior movimentação dos discursos presidenciais. As demais temáticas ficaram na faixa de quinze pronunciamentos, ou menos, ao longo de todo o período em análise, ou seja, mantiveram-se baixas e estáveis, sendo as com menores frequências: Circo $(0,1 \%)$, Outros $(0,6 \%)$, e Participação $(0,7 \%)$. 
Samira Chedid | Ana Cláudia Niedhardt Capella

Gráfico 6 - Discursos Presidenciais (2003-2014)

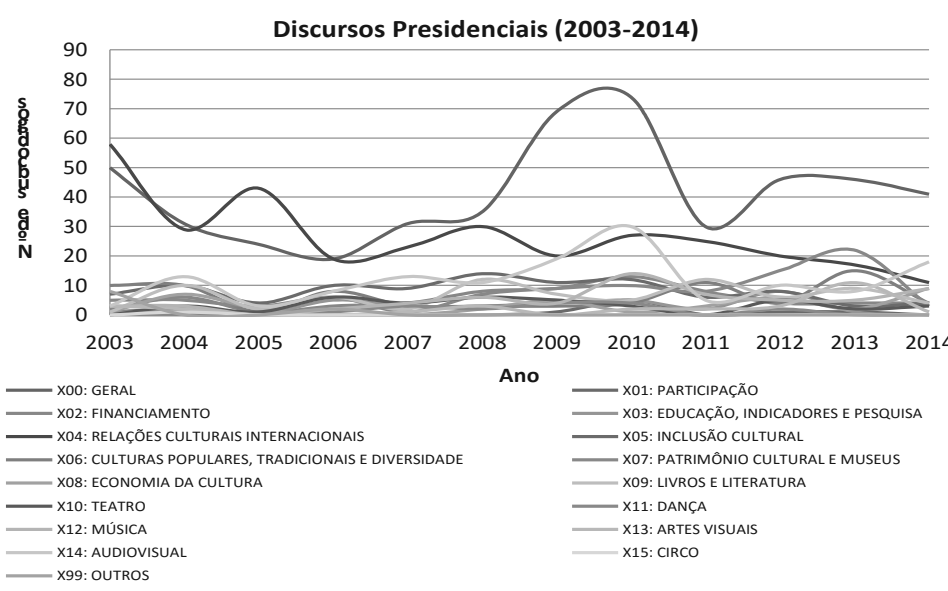

Fonte: Elaborado pelas autoras.

\subsubsection{Discursos do Ministério da Cultura}

Passando agora aos discursos proferidos pelos ministros e ministras de Cultura, ao iniciar a coleta, observou-se o ano de 2003 como o primeiro ano que disponibilizava os discursos publicamente por meio do site oficial do Ministério da Cultura. Com efeito, conforme ilustra o Gráfico 07, pode-se observar a movimentação dos subcódigos culturais ao longo do tempo. Os pontos mais altos ocorreram no ano de 2004 e 2007. São as pontuações que apontam mudanças. Já de 2009 em diante, todos os temas, embora mencionados, entram na estabilidade. Os anos com as menores frequências ocorreram em 2013 e 2014.

Em relação à temática mais discursada, o subcódigo Geral ficou com $17,9 \%$, seguida do Audiovisual com $16,8 \%$ e Patrimônio Cultural e Museus com 10,5\%. E, a menor frequência foi sobre o tema do Circo, com 0,4\%, Dança com 0,73\% e Teatro com 1,09\%. 
AGENDA GOVERNAMENTAL E POLÍTICAS CULTURAIS: ascensão e mudanças na policy image do Plano Nacional de Cultura

Gráfico 7 - Discurso dos (as) Ministros (as) de Cultura (2003-2014)

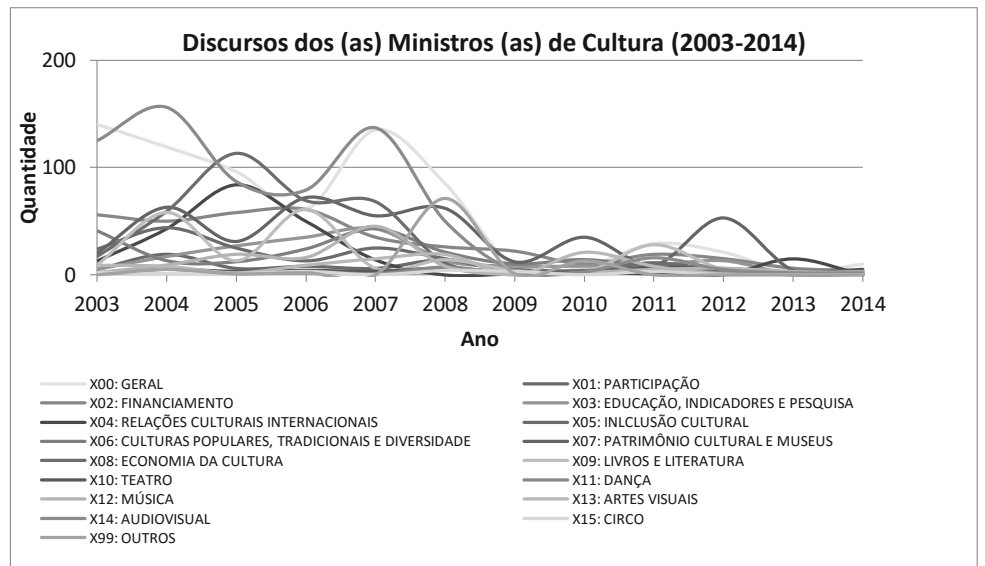

Fonte: Elaboração própria.

Nos discursos dos (as) ministros (as) de cultura, há uma distância na quantidade dos subcódigos encontrados. A maior frequência $(58 \%)$ ) ocorreu por meio de Gilberto Gil no primeiro mandato de Lula. No segundo mandato de Lula, com Gilberto Gil e Juca Ferreira, essa frequência foi para (32\%) e a maior discrepância ocorre no mandato de Dilma, com Ana de Hollanda e Marta Suplicy à frente do $\mathrm{MinC}$, com $10 \%$.

\section{O COMPORTAMENTO DAS IMAGENS DAS POLÍTICAS CULTURAIS}

Ao examinar a relação entre as 53 metas do $\mathrm{PNC}$ e os 17 subcódigos, observa-se a área das artes (teatro, dança, música, artes visuais e circo) com a menor incidência em ambos. Nas metas do PNC as artes aparecem somente na meta 22: "Aumento em 30\% no número de municípios brasileiros com grupos em atividade nas áreas de teatro, dança, circo, música, artes visuais, literatura e artesanato". Esse fato acompanhou a baixa frequência das artes nos subcódigos dos indicadores analisados. Por conseguinte, constata-se que a área das artes em geral recebeu pouca atenção na agenda governamental.

No que tange ao poder Legislativo, as unidades de codificação mostraram claramente o equilíbrio pontuado na produção legislativa oriunda do Congresso Nacional, pois foram três momentos 
de grande mudança com intervalos com maior estabilidade entre eles. Quanto ao Poder Executivo, no que se refere a sua produção legislativa, foi também possível aferir o equilíbrio pontuado, com a diferença, em relação ao Congresso Nacional, que o período pontuado pelas maiores mudanças se concentrou em três anos consecutivos, acrescentando outro momento de um ano no início do período (2003).

Ainda no âmbito do Executivo, mas agora em relação aos discursos presidenciais, estes apontaram que, ao Congresso pouco se falou sobre as políticas culturais, localizando-se apenas sete unidades de codificação. Nos demais discursos, a Presidência da República mencionou consideravelmente o conteúdo do PNC, porém, muitas vezes os termos foram usados indiscriminadamente, principalmente quando se tratava das relações internacionais, o que se aproximava mais de diplomacia do que da intenção de realizar ou incentivar políticas culturais em conjunto.

E, finalmente quais os temas centrais para o próprio Ministério da Cultura? Entre os assuntos mais mencionados estão o de caráter geral, seguido pelo audiovisual e a questão do patrimônio. Todos os demais subcódigos entraram nos discursos em algum momento, mas ainda se observa uma defasagem entre as temáticas. Quanto ao equilíbrio pontuado, foram observados dois momentos de grandes mudanças, sendo que ao findar o segundo momento, a queda ocorreu de forma brusca e a estabilidade acompanhou a baixa frequência dos subcódigos.

Ao comparar as agendas, podem-se identificar pontos em comum e distinções. A consonância é que em todas as agendas houve ao menos um pico de grande mudança, se comparada aos demais períodos da análise. $\mathrm{O}$ padrão de prioridades entre as agendas se condensou em assuntos de âmbito geral, patrimônio cultural e museus, audiovisual e financiamento. No tocante ao governo Lula e ao Governo Dilma, a partir do ano de 2011 (início do período Dilma), a produção legislativa na área cultural diminui. Os discursos de Dilma são poucos em relação ao segundo mandato de Lula, mas mais frequentes do que no primeiro mandato de Lula. Por outro lado, a relação com o Congresso através das Mensagens ao Congresso só existiu no governo Dilma. E, quanto aos discursos dos (as) ministros (as) de cultura, há uma distância grande entre os três mandatos. Decresceu da gestão de Gilberto Gil para Juca Ferreira e deste para Ana 
AGENDA GOVERNAMENTAL E POLÍTICAS CULTURAIS: ascensão e mudanças na policy image do Plano Nacional de Cultura

de Hollanda e Marta Suplicy. Por meio da análise de dados de forma conjunta, observamos três principais momentos que podem ser designados como estes períodos de pontuações. Se desmembrarmos a produção legislativa, observa-se a grande movimentação no ano de 2004, por intermédio do MinC, outro em 2009 tanto nos discursos presidenciais como na produção legislativa vinda do Poder Executivo e, no ano de 2011 há o auge nas Mensagens ao Congresso e na produção legislativa vinda do Congresso Nacional. Sendo que estes dois últimos momentos são os anos que cercam a aprovação do PNC como lei. Nos demais anos, há momentos de estabilidade. Desse modo, a atenção parte do MinC, se direciona ao Poder Executivo e depois para o Legislativo, sendo que a maior incidência das temáticas culturais nesses períodos representa os assuntos que entraram na agenda governamental.

Em suma, após a análise empírica, identifica-se a cultura como um problema público que precisava de uma solução. Anteriormente à solução, ou seja, o PNC ser apresentado, predominava-se o processo do feedback negativo. Nesse processo, o ambiente é de estabilidade, permeado por monopólios dos subsistemas onde a tendência é afirmar e defender suas próprias percepções, repelindo mudanças, novos atores e novas imagens. Contudo, é nos subsistemas que a estabilidade é rompida e iniciam-se debates para a melhoria das políticas culturais no Brasil.

Com efeito, a percepção das políticas culturais mudou, surgindo uma nova imagem (policy image) a seu respeito. Logo, a agenda governamental também mudou, quando novos atores se aproximaram do processo decisório. Ou seja, identificou-se um problema público e o PNC foi visto como a solução para este problema, que encontrou uma conjuntura política favorável, possibilitando debates e a sua aprovação, o que levou ao rompimento do feedback negativo, isto é, da situação de equilíbrio presente até então.

Surge, assim, o feedback positivo, que acontece quando um assunto se encontra no macrossistema, isto é, na agenda governamental, e em conjunto com novas imagens e venues interagem para mudar determinada política pública. Esta mudança pode ocorrer de maneira inesperada ou por meio de uma cascata de eventos. No caso das políticas culturais, esse momento aconteceu após a entrada de novos atores no processo decisório a partir do ano de 2003, onde já se expressa a intenção em formular um Plano Nacional de Cultura. 
Com o término do governo de Fernando Henrique Cardoso no ano de 2002, há uma mudança partidária e de ideologias no governo federal e assim novos atores despontam no processo decisório. No programa do governo democrático-popular do então candidato à presidência pelo PT (Partido dos Trabalhadores) Luiz Inácio Lula da Silva, o PNC é mencionado como uma prioridade ao entrar em circulação o documento intitulado A imaginação a serviço do Brasil: Programa de Políticas Públicas de Cultura (2002), que aponta a intenção do governo em se empenhar para a aprovação do PNC. Logo no ano de 2003, na gestão de Gilberto Gil, o Ministério da Cultura é reestruturado por meio do Decreto $\mathrm{n} 4.805$, de 12 de agosto de 2013. A atuação do MinC se amplia, passando à reformulação das secretarias, das representações regionais além de, posteriormente movimentar a participação social através do conselho e conferências nacionais.

Nesse sentido, é preciso ressaltar o papel das instituições e grupos sociais no desenvolvimento da mudança da agenda governamental, os chamados venues. Assim, somente após muitos debates nos contextos institucionais sobre as imagens de um problema chega a possibilidade de encontrar a melhor solução para resolvê-lo. Dessa maneira, após intensas discussões, tanto as imagens quanto os contextos institucionais são passíveis de mudança. Há uma influência mútua. Todavia, do mesmo modo, ambos podem ser resistentes a aceitar outras ideias. Esta situação fica clara quando observamos a Figura 01, visto que primeiro se intensificam as discussões sobre a policy image, e então vem a movimentação na legislação, levando a uma grande mudança nas políticas culturais através do PNC.

Após outra mudança de governo em 2011, logo após o PNC se tornar lei, mesmo mantendo o mesmo partido político, houve um movimento decrescente da atenção dada ao PNC e a seu conteúdo. Desse modo, a imagem foi regressando aos subsistemas, formando novos monopólios sobre o assunto. Com essa situação, retorna-se a situação de equilíbrio, já que as novas ideias e instituições são predispostas a permanecerem ao longo do tempo (policy legacy).

Apesar de todos os avanços do período em análise, e de todos os méritos do Plano Nacional de Cultura, as suas três dimensões -simbólica econômica e cidadã- não foram tratadas com total êxito. Ao longo deste trabalho, enfatizou-se a importância da gestão compartilhada e a participação da sociedade civil, mas a análise dos da- 
AGENDA GOVERNAMENTAL E POLÍTICAS CULTURAIS: ascensão e mudanças na policy image do Plano Nacional de Cultura

dos mostrou que o subcódigo Participação, parte da dimensão cidadã da cultura proposta no PNC, só apareceu nos discursos presidenciais $(0,7 \%)$ e nos discursos do MinC $(1,99 \%)$.

\section{CONCLUSÃO}

A política pública é um modo de olhar para um problema público e se configura como um processo para se atingir os objetivos de determinada área substantiva. Assim, não basta apenas a vontade e escolha de um único ator, pois surgem conflitos políticos e outras limitações para que a política pública aconteça, como insuficiência de recursos, de pessoal e financeiro, por exemplo. Desse modo, é essencial a análise da formação da agenda governamental em razão de que os assuntos que o governo detém atenção nesse período podem vir a se tornar uma política pública ou não.

Com efeito, esta pesquisa trouxe como objetivo principal identificar e analisar, na agenda governamental, os períodos de estabilidade e mudança do PNC ao longo de doze anos, desde o início da sua elaboração, até ser aprovado como Lei e começar a ser implementado, identificando, assim, o comportamento das policy images das políticas culturais através do PNC. Partiu-se da hipótese de que o PNC se manteve estabilizado dentro do monopólio do setor cultural e chega à agenda do macrossistema somente após a entrada de novos atores governamentais no ano de 2003, passando a fazer parte, efetivamente, da agenda governamental. Para comprovar esta hipótese, definiram-se dois indicadores da referida agenda: o Poder Executivo e o Poder Legislativo, e então localizou-se a documentação específica de cada indicador para que todos fossem representados.

Para a classificação dos dados, utilizou-se o método da análise de conteúdo, onde os dados foram alocados em unidades de codificação que denominamos de subcódigos. Os dados coletados das diferentes agendas tiveram seu conteúdo codificado e, por fim, sistematizados e analisados, permitindo medir a atenção dada à área cultural na agenda do Poder Executivo e do Poder Legislativo.

Em virtude do que foi desenvolvido ao longo deste trabalho, conclui-se que as políticas culturais no Brasil ainda não atraíram de forma eficaz a agenda governamental, pois embora tenham dado um grande salto a partir da formulação do PNC, onde se nota uma "ebulição" quando o assunto adentra a agenda governamental, a partir de 
variados discursos e propostas legislativas de temáticas que fazem parte do PNC, por outro lado, após se tornar lei, o assunto decresceu.

Segundo a Teoria do Equilíbrio Pontuado, o issue está presente nos subsistemas políticos onde se formam monopólios sobre a questão. Ou seja, o assunto é debatido por especialistas, ou por quem convive frequentemente com esta realidade. Após este período de estabilidade, o issue tem maiores chances de ascender ao macrossistema da política, isto é, entrar na agenda governamental. Durante esse percurso, a percepção do assunto em pauta pode sofrer modificações de acordo com o contexto institucional e dos atores em jogo: são as policy images. Por meio desta pesquisa, observou-se a proeminência do tema do financiamento nos discursos e legislação (embora aqui não se discrimine o destino dos recursos), seguido das questões referentes ao patrimônio cultural, o audiovisual e assuntos de caráter geral, sendo, este último, temas que englobam os demais. Por outro lado, as artes como um todo foram ofuscadas. E é principalmente no primeiro ano de cada mandato presidencial que se concentra a produção legislativa e os discursos, decaindo nos anos subsequentes. Assim, os resultados mostraram que a imagem do PNC chegou ao ápice em determinados períodos permeados por intervalos estáveis, fato que nos permite afirmar a existência de mudanças na percepção das políticas culturais dentro da agenda governamental.

\section{REFERÊNCIAS}

BAUMGARTNER, F. R; JONES, B. D. Agendas and Instability in American Politics. Chicago: University of Chicago Press, 1993.

$\overline{\text { Press, } 20} \overline{02 .}$ Policy dynamics. Chicago: University of Chicago

; _ _ ; MORTENSEN, P. B. Punctuated equilibrium theory: explaining stability and change in public policymaking. In: SABATIER, P. A.; WEIBLE, C. M. Theories of the policy process. 3. ed. Boulder: Westview Press, 2014.

BRASIL. Misnistério da Cultura. Discursos. Brasília, DF, [20--?]. Disponível em:<http://www.cultura.gov.br/discursos>. Acesso em: 7 set. 2016. 
AGENDA GOVERNAMENTAL E POLÍTICAS CULTURAIS: ascensão e mudanças na policy image do Plano Nacional de Cultura

\section{Notas:}

1 Somente a partir de 2003 observa-se uma maior articulação do MinC.

2 A metodologia de análise de conteúdo propõe o uso de unidades de codificação para a análise de documentos textuais, ou seja, a utilização de recortes do texto (que podem ser trechos, palavras ou temas) para posterior categorização e análise. Nessa perspectiva, as palavras, temas ou trechos selecionados do corpus documental, foram alocadas em categorias temáticas previamente definidas na área das políticas culturais, constituindo assim, um banco de dados sobre a frequência com que determinados tópicos aparecem nos documentos analisados.

3 Informações disponíveis na Rede de Informação Legislativa e Jurídica (Disponíveis em: $<$ http://www.lexml.gov.br/>).

4 Disponíveis no site virtual do Palácio do Planalto da Presidência da República (Disponível em:<http://www2.planalto.gov.br/acompanhe-o-planalto/mensagem-ao-congresso $>$ ).

5 Temáticas das Políticas Culturais: código e subcódigos

${ }^{\mathrm{x} 00}$ Geral: Plano Nacional de Cultura; Sistema Nacional de Cultura, Pontos de Cultura; Mais Cultura; Cultura Viva; demais programas com abrangência geral e, o conceito "cultura" isoladamente.

${ }^{\mathrm{x} 01}$ Participação: Conferências, Conselhos, participação da sociedade civil

${ }^{\mathrm{x} 02}$ Financiamento à cultura: Orçamento, fundos; ProCultura; fomento, investimento, patrocínios

${ }^{\mathrm{x} 03}$ Educação, indicadores e pesquisa: Disciplinas, e atividades de qualquer ramo artístico, oferecidas nas escolas, universidades ou outro espaço; profissionalização ou especialização; intercâmbio; Sistema Nacional de Informações e Indicadores Culturais; gestão cultural, pesquisas acadêmicas; seminários; congressos; informações e indicadores em geral

${ }^{\mathrm{X} 04}$ Relações Culturais Internacionais: Relações culturais com outros países; eventos internacionais

${ }^{\mathrm{x} 5}$ Inclusão Cultural: Portadores de deficiência física ou mental; baixa-renda; inclusão cultural; acessibilidade

${ }^{\mathrm{X} 06}$ Culturas populares, tradicionais e Diversidade: Todas as questões referentes às culturas populares, tradicionais e indígenas; LGBT, Mulheres, Ciganos, Negros, crenças e religiosidade

${ }^{\mathrm{x} 7}$ Patrimônio cultural e museus: Patrimônio material e imaterial; prédios históricos, tombamentos, exposições, bienais, memoriais

${ }^{\mathrm{x} 0}$ Economia da Cultura: Economia Criativa, atividades econômicas no âmbito cultural; indústria cultural; Vale-cultura

${ }^{\mathrm{X} 09}$ Livros e literatura: Bibliotecas; livros; literatura; PNLL, incentivo à leitura, linguagem,

${ }^{\mathrm{x} 10}$ Teatro: Todas as atividades relacionadas ao teatro

${ }^{\mathrm{X} 11}$ Dança: Todas as atividades relacionadas à dança

${ }^{\mathrm{X} 12}$ Música: Todas as atividades relacionadas à música

${ }^{\mathrm{x} 13}$ Artes visuais: Artes plásticas, arquitetura, artesanato, moda e design

${ }^{\mathrm{x} 14}$ Audiovisual: Cinema; conteúdo cultural televisivo; Cultura Digital

${ }^{\mathrm{X} 15}$ Circo: Atividades circenses em geral

${ }^{\mathrm{X} 99}$ Outros: matérias não incluídas nos tópicos anteriores que não sejam de caráter geral

$6 \mathrm{Na}$ conjuntura desta pesquisa, foram coletados 172 documentos, sendo $02 \mathrm{ECs}, 07 \mathrm{MPs}, 43$ Leis, 120 PLs e nenhuma Lei Complemnetar (LC). No caso dos Projetos de Lei, 40 foram aprovados.

7 Por exemplo: diversidade cultura, cultura brasileira, carnaval.

8 Não houve leis complementares no período em análise, e as Medidas Provisórias não são propostas pelo Poder Legislativo. 
